\title{
Antibacterial Mesoporous Titania Films with Embedded Gentamicin and Surface Modified with Bone Morphogenetic Protein 2 to Promote Osseointegration in Bone Implants
}

\author{
Ane Escobar, Nicolás Muzzio, Emerson Coy, Hui Liu, Elisa Bindini, Patrizia Andreozzi, \\ Guocheng Wang, Paula Angelomé, Mihaela Delcea, Marek Grzelczak, \\ and Sergio E. Moya*
}

Novel approaches are needed to avoid bacterial infections following implant surgery. Here the use of mesoporous titania films (MTFs) for gentamicin loading and delivery and the surface functionalization of MFTs with human recombinant bone morphogenetic protein 2 (hrBMP-2) are discussed. Gentamicin is incorporated into the MTF pores by immersion of the porous materials in gentamicin solution while hrBMP-2 is adsorbed on top of the MTF. Contact angle and X-ray photoelectron spectroscopy measurements are performed to prove gentamicin loading and hrBMP-2 functionalization. An initial burst release of gentamicin takes place in physiological media followed by a prolonged release that lasts weeks. Such a release profile is highly appealing for bone implants where a high concentration of antibiotics is necessary during implant surgery while a lower antibiotic concentration is needed until tissue is regenerated. The MTFs loaded with gentamicin and functionalized with hrBMP-2 are effective against Staphylococcus aureus colonization, and the presence of hrBMP-2 enhances MC3T3-E1 preosteoblastic cell attachment, proliferation, and differentiation.

surgery and implant replacement, which are costly and compromise the health of the patient. A major reason for the failure of implants is the development of bacterial infections at the site of implant. During bone surgery, the surface of the implants is susceptible to bacterial infections that can lead to the formation of a biofilm and to a compromised immune response at the site of the implant. Aseptic loosening of the implants following surgery can result in the premature failure of the implant due to poor osseointegration. ${ }^{[5,6]}$ Staphylococcus aureus is among the most common bacteria causing implant-associated infections and is considered to be a major, virulent pathogen that colonizes and infects both hospitalized patients with decreased immunity and healthy immunocompetent people. ${ }^{[7,8]}$ Skin and mucous membranes are excellent barriers against local tissue invasion by $S$. aureus, but if any of

\section{Introduction}

Since bone and joint inflammatory problems account for $50 \%$ of chronic diseases in developed countries, ${ }^{[1]}$ there is an urgent demand for mechanically resistant and bone-compatible orthopedic implants. ${ }^{[2-4]}$ Implants often fail, requiring additional

Dr. A. Escobar, Dr. N. Muzzio, Dr. E. Bindini, Dr. P. Andreozzi,

Dr. S. E. Moya

Soft Matter Nanotechnology Laboratory

CIC biomaGUNE

Paseo de Miramón 182, 20014 Donostia-San Sebastián, Spain

E-mail: smoya@cicbiomagune.es

Dr. E. Coy

NanoBioMedical Center

Adam Mickiewicz University

Umultowska 85, 61-614 Poznan, Poland

H. Liu, Dr. G. Wang

Research Center for Human Tissues \& Organs Degeneration

Shenzhen Institute of Advanced Technology

Chinese Academy of Science

Shenzhen, Guangdong 518055, China

The ORCID identification number(s) for the author(s) of this article can be found under https://doi.org/10.1002/admi.201801648.

DOI: 10.1002/admi.201801648 them is breached due to trauma or surgery, bacteria can enter the underlying tissue, creating their characteristic local abscess lesion. ${ }^{[9,10]}$ Antibiotics are normally locally administered at the implant site, which effectively avoids the formation of bacterial colonies during surgery. However, there is a risk of bacterial colonization during the time bone tissue is being regenerated,

\author{
Dr. P. Angelomé \\ Gerencia Química-Centro Atómico Constituyentes \\ Comisión Nacional de Energía Atómica \\ CONICET \\ Avenida General Paz 1499, B1650KNA San Martín, Buenos Aires, \\ Argentina \\ Prof. M. Delcea \\ Nanostructure Group \\ ZIK HIKE \\ University of Greifswald \\ Fleischmannstraße 42-44, 17489 Greifswald, Germany \\ Dr. M. Grzelczak \\ Ikerbasque \\ Basque Foundation for Science \\ 48013 Bilbao, Spain \\ Dr. M. Grzelczak \\ Donostia International Physics Center \\ Paseo de Manuel Lardizabal 4, 20018 Donostia-San Sebastián, Spain
}


which last several weeks, until the protective capsule is formed and especially after surgery when the osseointegration processes has started. To ensure the successful implant adaptation, a rational supply of antibiotics is needed and can be achieved by modifying the implant surface with antibiotics-loaded polymer coatings such as polyelectrolyte multilayers, brushes, or hydrogels. ${ }^{[1-14]}$ However, the main challenge is to obtain a localized supply of the antibiotics with a two-phase release profile. An initial burst release at short times is highly desirable as, during surgery and at initial phase during bone formation, the risk of bacterial infection is larger, and a slow release that lasts weeks is required while the capsule is getting regenerated.

By favoring cell adhesion to the implant, tissue regeneration is promoted; thus, the risk of bacterial infections is diminished. ${ }^{[15-17]}$ This can be achieved by different ways: modifying implant topography or using bioactive ions and growth factors. Mechanical properties, the resistance to corrosion and wear, as well as osseointegration and biocompatibility are some of the properties that the biomaterial should exhibit when selecting a candidate for bone replacement. ${ }^{[18]}$ Depending on the type of bone, the modulus of elasticity varies between 4 to $30 \mathrm{GPa}{ }^{[19]}$ Titanium and titanium alloys are recognized as good materials for orthopedic implants due to their osseocompatibility and bone-bonding capacity. ${ }^{[18,20-25]}$ Currently used commercial titanium implants satisfy the required mechanical properties with a Young's modulus within the range of $100-120 \mathrm{GPa}^{[26]}$ Coating the implant surface with a mesoporous film is an attractive method to improve biocompatibility, as rougher surfaces promote bone and implant interlocking. ${ }^{[2,24,27]}$ Mesoporous materials have an ordered, homogeneous distribution of interconnected pores whose diameters are in the $2-50 \mathrm{~nm}$ range. ${ }^{[28-35]}$ Titania can be synthesized as a mesoporous material without compromising its mechanical properties, ${ }^{[36]}$ which are fundamental for bone replacement. Mesoporous titania can be used for drug loading by soaking it in a drug solution, and once drugs

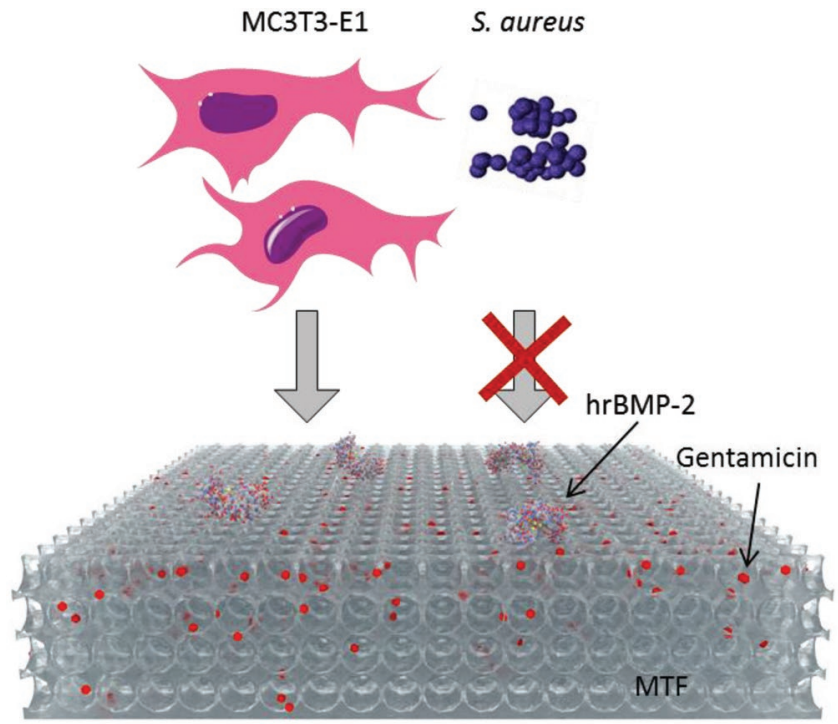

Figure 1. MTF loaded with gentamicin and with hrBMP-2 on the surface to enhance MC3T3-E1 preosteoblastic cell attachment and differentiation and avoid S. aureus attachment. are entrapped, their release is slowed by the necks that interconnect the mesopores. ${ }^{[37,38]}$ Atefyekta et al. ${ }^{[39]}$ have studied the loading and release of gentamicin, vancomycin, and daptomycin from mesoporous titania films (MTFs) of pore sizes ranging from 4 to $7 \mathrm{~nm}$, but the release of the antibiotics from the MTFs has been shown to occur within the first $80 \mathrm{~min},{ }^{[39]}$ which is not desirable for implants, where an initial burst release followed by a prolonged one is needed. ${ }^{[16]}$

Here we show that the loading of MTFs with antibiotics and its surface functionalization with growth factor proteins improve the antibacterial properties of titania and promote the preosteoblasts proliferation and differentiation, as sketched in Figure 1. We used gentamicin (Chart S1, Supporting Information) to load a mesoporous titania film of $90 \mathrm{~nm}$ thickness and $5.7 \mathrm{~nm}$ in pore diameter, prepared by spin coating through the evaporation-induced self-assembly (EISA) method. In contrast to previous studies, ${ }^{[40-43]}$ we demonstrate here that while $36 \%$ of the gentamicin is released within the first $6 \mathrm{~h}$, gentamicin release is prolonged over 35 days. The antibacterial properties of the mesoporous titania are further enhanced by immobilizing a growth factor-the human recombinant bone morphogenetic protein 2 (hrBMP-2) - on the surface of the film, favoring cell attachment and growth. While the antibacterial action of the gentamicin-loaded MTF was tested against $S$. aureus, the proliferation, adhesion, and differentiation assays were performed with the MC3T3-E1 preosteoblastic cell line.

\section{Results and Discussion}

\subsection{MTF Synthesis and Functionalization with hrBMP-2 and Gentamicin Loading}

To obtain the mesoporous thin films, we implemented the wellknown EISA method that comprises hydrolysis and condensation of titania precursors in the presence of block copolymer Pluronic F127. The porous structure is confirmed by transmission electron microscopy (TEM) and scanning electron microscopy (SEM) characterization (Figure 2a,b). The inset in Figure 2a shows the 2D-small angle X-ray scattering (2D-SAXS) pattern of the MTF. The elliptic shape of the pattern suggests the presence of multiple domains of locally ordered pores. ${ }^{[44]}$ Calculated interplanar distances show interpore distances of 11.5 and $3.9 \mathrm{~nm}$ in the $(-110)$ and (110) planes, respectively. The contraction due to the calcination process at $350^{\circ} \mathrm{C}$ is of $65 \%$, calculated from differences in the interpore distances at $(-110)$ and (110) planes. ${ }^{[45]}$ From the analysis of water adsorption-desorption isotherms (Figure 2d) obtained by environmental ellipsomtric porosimetry (EEP), it can be concluded that the MTF has a porosity of $30.7 \%$ and a pore size of $5.7 \mathrm{~nm}$ in diameter connected by necks of $4.2 \mathrm{~nm}$ in diameter. The film thickness was of $80 \mathrm{~nm}$, a value which is in agreement with the thickness of around $90 \mathrm{~nm}$ obtained from the SEM image of the transversal cut of the MTF (Figure 2c).

Nanoindentation measurements are presented in Figure S1 (Supporting Information). They showed an elastic modulus of $25 \pm 5 \mathrm{GPa}$, smaller than the value for dense titanium surfaces, which is ranged between 100 and $120 \mathrm{GPa} \cdot{ }^{[26]}$ Nevertheless, it is in agreement with the range of elastic modules of bones, 

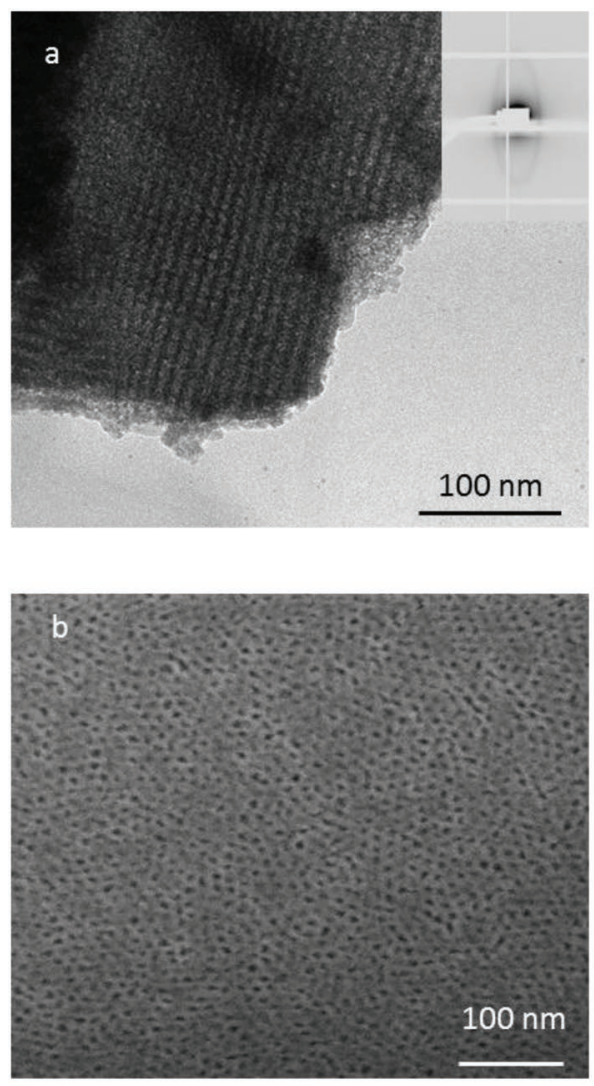
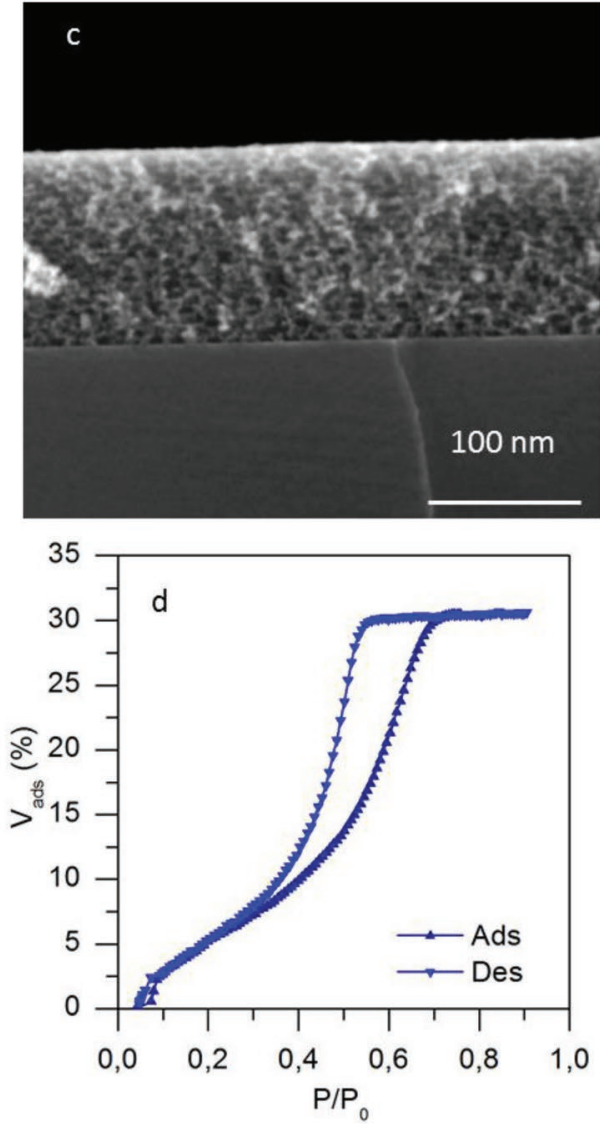

Figure 2. Mesoporous titania film (MTF) structural characterization by electron microscopy, 2D-SAXS, and EEP. a) TEM image, inset: 2D-SAXS pattern; b) SEM image of the surface, c) SEM image of a transversal cut, and d) EEP of water vapor adsorption and desorption.

which lies between 4 and 30 GPa depending on bone type, ${ }^{[19]}$ and values reported for porous titania films. ${ }^{[46]}$

MTFs were functionalized with hrBMP-2 and loaded with gentamicin. To confirm the presence of both hrBMP-2 and gentamicin, the atomic percentage of S/Ti was quantified through high-resolution X-ray photoelectron spectroscopy (XPS) spectra in the spectral range of sulfur (S) and titanium (Ti) (Figure S2, Supporting Information). The peak corresponding to $S 2 p_{3 / 2}$ is more pronounced in the MTF loaded with antibiotic, coated with protein, or containing the mixture of both, as compared to the bare MTF. Although there was no S for the bare MTF, a S/Ti atomic relative percentage of $0.41 \pm 0.09 \%$ was obtained, which corresponds to environmental contamination of the equipment. When the MTF was loaded with gentamicin, the S/Ti relative percentage increases to $2.03 \pm 0.09 \%$. If the MTF was functionalized with hrBMP-2 prior to gentamicin loading, the S/Ti relative percentage is $3.44 \pm 0.99 \%$. The $\mathrm{S} / \mathrm{Ti}$ ratio for the MTFs functionalized with hrBMP-2 and loaded with gentamicin was $1.48 \pm 0.32 \%$. The decrease in $\mathrm{S}$ content for the mesoporous film with hrBMP-2 and gentamicin could be a consequence of partial removal of hrBMP-2 due to the loading conditions of gentamicin, as suggested by atomic force microscopy (AFM) experiments (see Figure 4g), and also may mean that hrBMP-2 adsorbed on the surface of MTFs partially blocks the access to the pores for gentamicin, diminishing the loading; however, the calculated standard error is high and the difference in the relative percentage is not significant between the MTF with gentamicin and the MTF with gentamicin and BMP-2. Additional proof of the loading and functionalization was obtained from contact angle measurements. Figure 3 shows the changes in contact angle of water following hrBMP-2 functionalization and gentamicin loading. Bare MTF had a contact angle of $13.4^{\circ} \pm 0.30^{\circ}$ (Figure 3a). When the MTF was loaded with gentamicin or functionalized with hrBMP-2, the contact angle changed to $73.15^{\circ} \pm 1.07^{\circ}$ (Figure 3b) and $72.47^{\circ} \pm 2.60^{\circ}$ (Figure $3 \mathrm{c}$ ), respectively. For the MTF functionalized with hrBMP-2 and loaded with gentamicin, the contact angle increased to $90.95^{\circ} \pm 2.19^{\circ}$ (Figure 3d). Changes in contact angle confirmed the loading of gentamicin and the modification with the growth factor. Furthermore, the deposition of hrBMP-2 on the MTFs was quantified by means of the quartz crystal microbalance with dissipation (QCMD). MTFs were assembled on top of quartz crystal sensors and exposed to hrBMP-2 solution in the QCMD chamber. For hrBMP-2 with a concentration of $1000 \mathrm{ng} \mathrm{mL}^{-1}$, we recorded a deposition of $60 \mathrm{ng} \mathrm{cm}^{-2}$. For the $100 \mathrm{ng} \mathrm{mL} \mathrm{m}^{-1}$ solution, the QCMD was not capable of detecting the deposited mass of hrBMP-2. The changes in frequency for the deposition of $1000 \mathrm{ng} \mathrm{mL}^{-1}$ BMP-2 solution are shown in Figure S3 (Supporting Information). Mass was calculated applying the Sauerbrey equation.

Gentamicin loading is proved by release experiments and by measuring the antibacterial properties of the MTF after loading. Proliferation and differentiation assay confirm the 
MTF

a

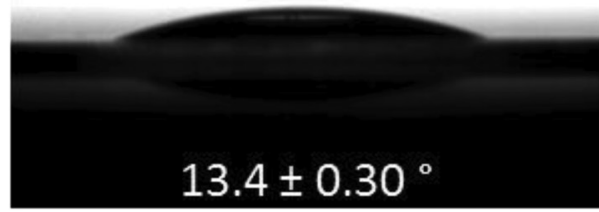

MTF + BMP $100 \mathrm{ng} / \mathrm{mL}$

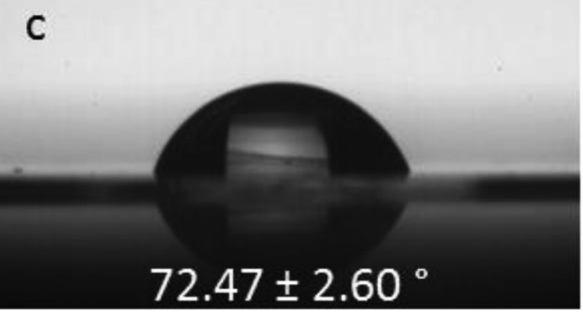

MTF + gentamicin

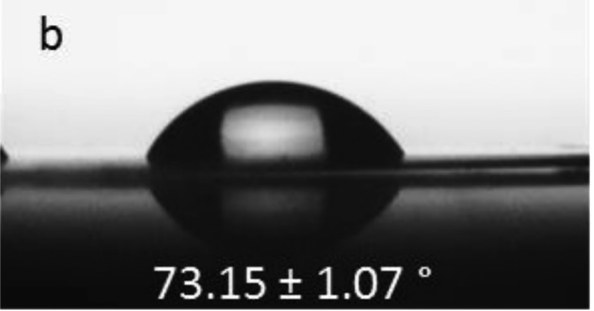

MTF + BMP $100 \mathrm{ng} / \mathrm{mL}+$ gentamicin

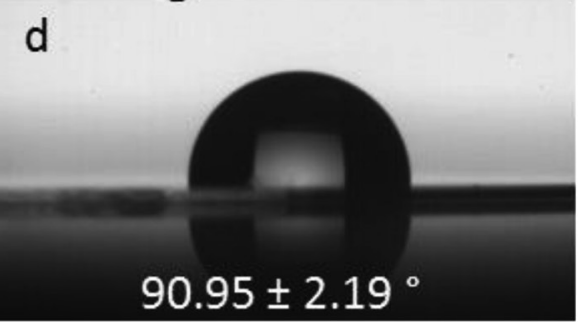

Figure 3. Contact angle measurements. a) Bare MTF b) MTF with gentamicin, c) MTF with hrBMP-2 $100 \mathrm{ng} \mathrm{mL}^{-1}$, and d) MTF with hrBMP-2 $100 \mathrm{ng} \mathrm{mL}^{-1}$ and gentamicin.

presence of hrBMP-2 as well. Release experiments showed a release of $3.57 \mu \mathrm{g}$ of gentamicin over 35 days. The release as we will show later reaches a plateau after 28 days. We can assume that all the gentamicin has been liberated after 35 days and that the amount of gentamicin released coincides with the loading. Moreover, more important than the loading is the amount of gentamicin that will be released from the mesoporous and will be responsible for the antibacterial action. We will take the total amount of released gentamicin as the actual effective loading of the mesoporous.

MTF displayed a smooth surface as confirmed by AFM imaging (Figure $4 \mathrm{a}-\mathrm{c}$ ), with a roughness of around $190 \mathrm{pm}$. When the protein was deposited on top of the MTF, roughness increases to $250 \mathrm{pm}$, meaning that the surface loses homogeneity but confirming the presence of hrBMP-2 (Figure 4f). The height profile singularities with a few nanometers in thickness can be recognized, which were not observed in the bare MTF. Phase image also confirms the presence of a different material on top of the MTF (Figure 4e); when the height changes, a phase shift is also detected. When the MTF functionalized with hrBMP-2 was loaded with gentamicin, some hrBMP-2 was loosed from the surface (Figure $4 \mathrm{~g}$ ) and the roughness decreased to $210 \mathrm{pm}$ (Figure 4i). In the AFM image, the presence of proteins on the MTF is indicated with blue arrows.

\subsection{Gentamicin Release from MTFs}

The release profile of the gentamicin is plotted in Figure 5 as the total amount of released gentamicin (Figure 5a) and as the percentage of gentamicin released (Figure $5 \mathrm{~b}$ ). The percentages are calculated assuming that after 35 days all gentamicin has been released from MTF in agreement with the plateau in the amount of released gentamicin observed after day 28 in Figure 5a. After 35 days $3.57 \mu \mathrm{g}$ of gentamicin was released. In the figure we can observe that there was a fast release at initial times and within the first $6 \mathrm{~h}$ around the $36 \%$ of the total liberated gentamicin was released. This initial burst release is required to avoid bacteria to adhere and infect the implant during the surgery. This period is known to be the riskiest period for infection. After the burst release, a second slower and prolonged release took place. The second release profile is within the time frame required for the implant to be integrated in the tissue and for the formation of the protective fibrous capsule. ${ }^{[4]}$ This second release step suggests that gentamicin is retained inside the pores interacting with the titania surface. Angelomé and Soler-Illia have shown that hydroxyl groups in dialcohols can be incorporated onto the MTFs by complexation of the $\mathrm{Ti}(\mathrm{IV})$ centers present in the pore surface. ${ }^{[48]}$ Moreover, they have demonstrated that different amounts of dialcohols can be released in aqueous solution, depending on the medium's $\mathrm{pH}$. Thus, gentamicin can be anchored to the titania surface through oxo bridges due to the presence of three hydroxyl groups in the molecule, which would explain the slow release of gentamicin from MTFs. Gentamicin can also adhere to the MTF walls electrostatically. The presence of gentamicin linked to the pore walls by complexation and by electrostatic interactions could explain the irregularities observed in the release profile. Gentamicin electrostatically bound should be more easily released as the interaction with titania is weaker than when gentamicin forms a complex through oxo bridges.

Our results on gentamicin liberation are quite different from Atefyekta et al., ${ }^{[39]}$ where a fast release of gentamicin takes place in around 80 min from mesoporous titania with pore sizes similar to ours. A possible reason could be that the mesoporous structure in our films may have narrowed necks and higher 

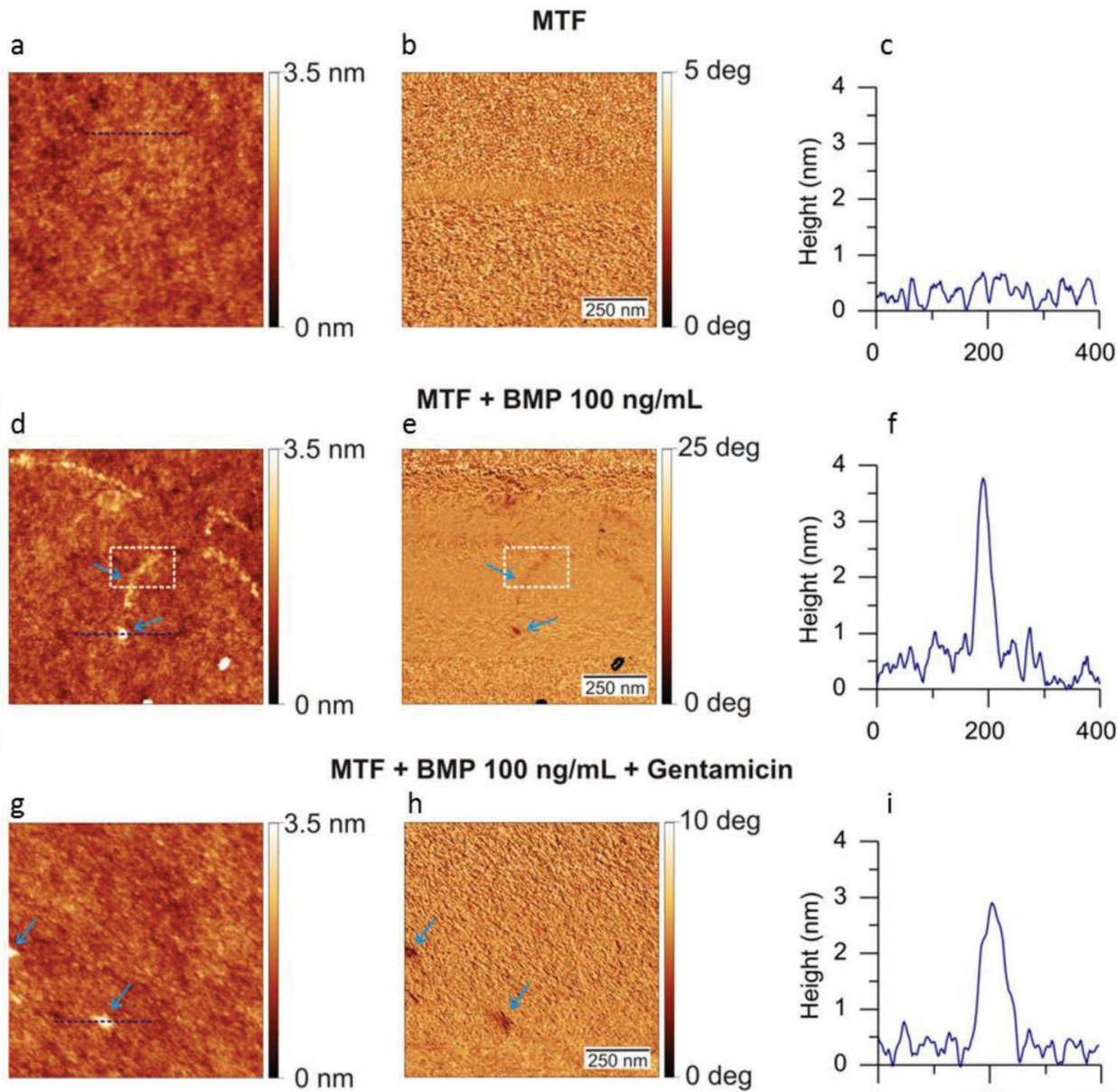

MTF + BMP $100 \mathrm{ng} / \mathrm{mL}$ + Gentamicin
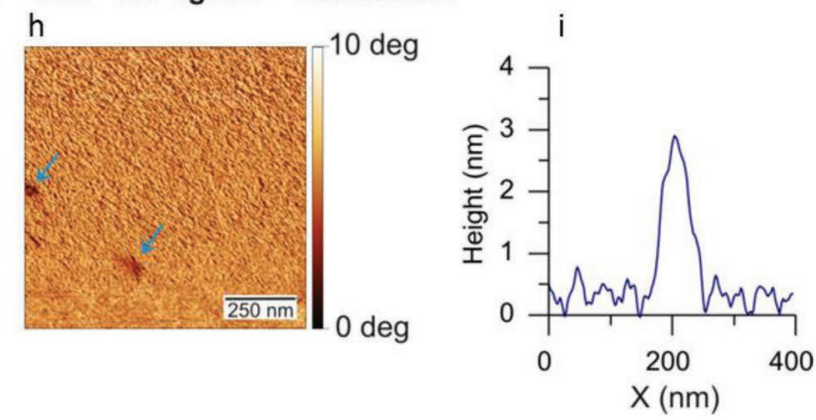

Figure 4. AFM images (height, phase, and height section) of MTF, MTF with hrBMP-2 $100 \mathrm{ng} \mathrm{mL}^{-1}$, and MTF with hrBMP-2 $100 \mathrm{ng} \mathrm{mL}^{-1}$ and loaded gentamicin. a) height, b) phase, and c) section of MTF substrates; d) height, e) phase, f) section of MTF with hrBMP-2 $100 \mathrm{ng} \mathrm{mL}^{-1}$ substrate, showing an increase in the height, and g) height, similar to MTF with hrBMP-2 $100 \mathrm{ng} \mathrm{mL}^{-1}$ sample, h) height and i) section image of MTF with hrBMP-2 $100 \mathrm{ng} \mathrm{mL}^{-1}$ and loaded with gentamicin.

tortuosity, resulting in only a $36 \%$ of gentamicin to be released as gentamicin diffusion through the pore mesh is more hindered. Moreover, Atefyekta et al. ${ }^{[39]}$ have measured gentamicin loading and release by QCMD from MTF deposited on top of CMD crystals. Both upload and release were measured from variations in the frequency of the crystal, and for release studies the authors apply a continuous flow of phosphate buffered saline (PBS) at a flux of $50 \mathrm{~mL} \mathrm{~min}{ }^{-1}$, which is a relatively high flux and should trigger a faster liberation of gentamicin. In our case, the release is performed in static conditions. In their work, Atefyekta et al. ${ }^{[39]}$ have recognized that the release is fast and related it to the methodology used for measuring antibiotic release, which seems a major reason for the differences observed between their results and the present work.

\subsection{Biocompatibility and Bioactivity Evaluation}

Initial cell adhesion on biomaterials plays a key role on cell proliferation, migration, and differentiation. The focal adhesions
(FA) and extracellular matrix (ECM) interactions involve integrins that bind different ECM proteins with the external end and cytoskeleton via adapter proteins such as talin, $\alpha$-actinin, filamin, and vinculin. FAs are based on this integrin-adapter protein-cytoskeleton complex. Osteoblasts anchor on substrate surface via integrin receptors, which are involved in processes named as "outside-in-signaling" and "inside-out-signaling" between the ECM and the cell. These pathways involving integrins can regulate subsequent cell adhesion, migration, proliferation, and differentiation. ${ }^{[49,50]}$

The MC3T3-E1 osteoblast precursor cell line was used to evaluate adhesion to the functionalized MTFs. Figures S4 and S5 (Supporting Information) and Figure 6 show confocal laser scanning microscope (CLSM) images of the cells cultured on the bare MTFs, MTFs functionalized with hrBMP-2, and MTFs functionalized with hrBMP-2 and gentamicin, respectively. The actin filaments (F-actin) were stained with phalloidin; thus, they are represented in red in the second row. Vinculin was stained with fluorescein isothiocyanate (FITC), in green, in the first row. The nucleus was stained with 
a

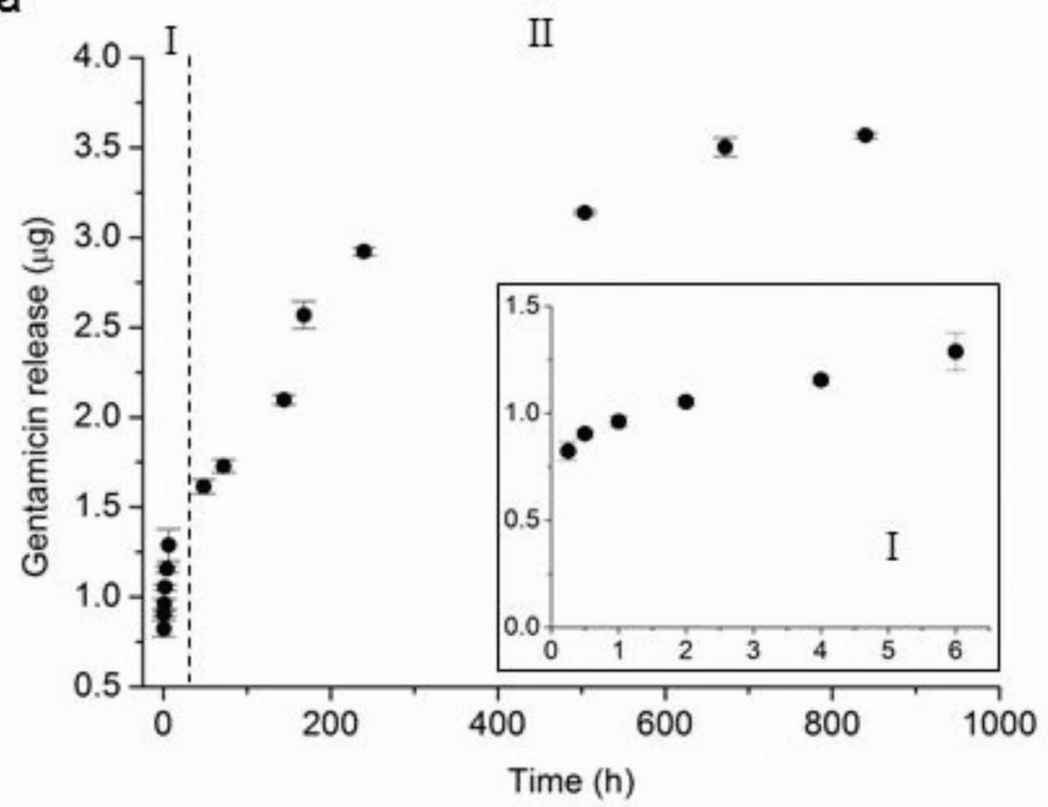

b

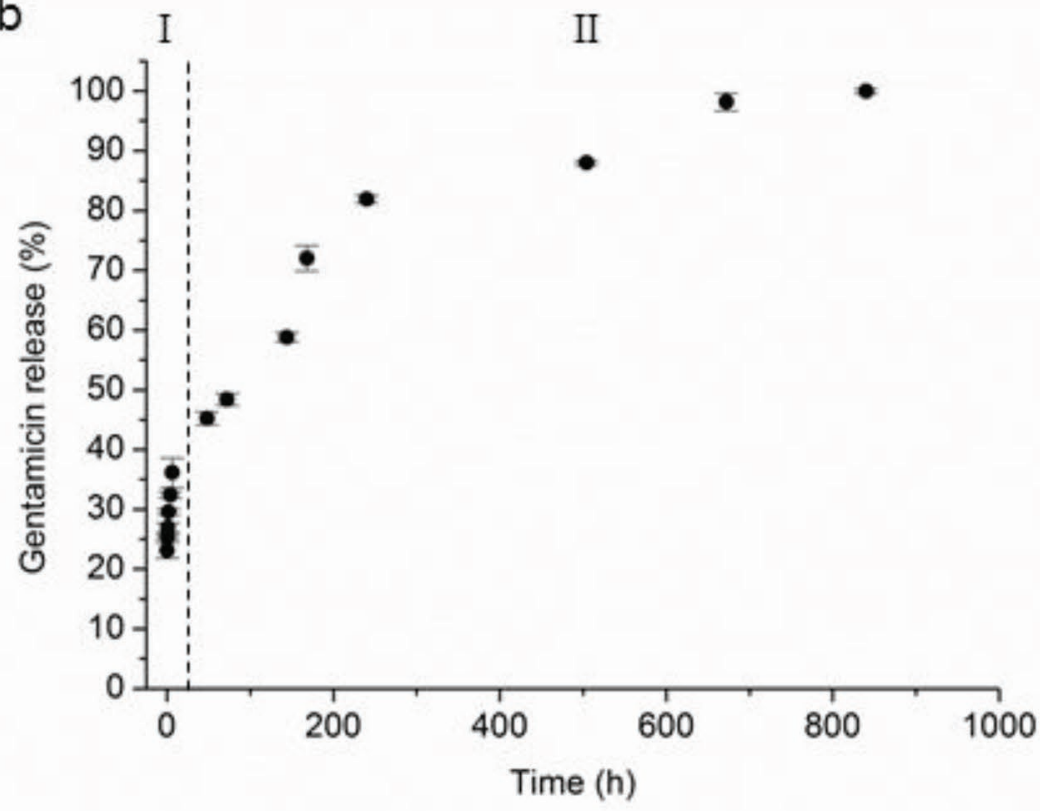

Figure 5. Release profile of gentamicin from MTF. Region I shows the burst release (the inset is a zoom of region I) and region II the sustainable release. The release is followed up to 35 days and followed by emission measurements at $455 \mathrm{~nm}$. Results are shown as total gentamicin released in $\mu \mathrm{g}$ a) and percentage of released gentamicin b). Percentage of released gentamicin is calculated assuming that at day 35 a $100 \%$ of gentamicin has been released.

4,6-diamidino-2-phenylindole (DAPI) and is represented in blue in the merge images (third row), where all the labeled cell parts are shown. From the F-actin images can be seen that cultured cells in the three substrates exhibited a similar size and an arranged cytoskeleton with distinctive stress fibers inside the cytoplasm, especially at the border of the cells. However, the cell shape was different after $48 \mathrm{~h}$ of culture (third column). When the MTF was modified with hrBMP-2 (Figure
S4, Supporting Information), the cell shape was more elongated if compared with cells cultured $48 \mathrm{~h}$ on the bare MTFs (Figure S5, Supporting Information) or hrBMP-2 and gentamicin (Figure 6). This cell shape and higher filopodia ${ }^{[51]}$ means cells were interacting better when hrBMP-2 was present on the surface and were well attached. This does not mean that cell attachment was not good on the other substrates, on which focal adhesion points and a well-arranged cytoskeleton were as well present.

Focal adhesions allow cells to interact with the surrounding environment; vinculin can interconnect signals in the focal adhesions and is a key regulator. ${ }^{[52,53]}$ In the vinculin staining images (first row), in all substrates, lots of green spots can be found. After $2 \mathrm{~h}$ of cell incubation on the substrates (first column), focal adhesions can also be perfectly distinguished, meaning that cells adhered well to the substrates from initial times, which would improve later cell proliferation. ${ }^{49,52]}$

To study the influence of the hrBMP-2 and gentamicin on cell proliferation, cells were cultured in substrates coated with hrBMP-2, coated with hrBMP-2 and loaded gentamicin, and only loaded with gentamicin. hrBMP-2 was deposited on the MTF from solutions with 10 and $100 \mathrm{ng} \mathrm{mL}^{-1}$ hrBMP-2. Results are plotted in Figure 7. Data from MTFs coated with hrBMP-2 shown in the figure correspond only to experiments performed with $100 \mathrm{ng} \mathrm{mL}^{-1}$ hrBMP-2. A comparison between the effects of hrBMP-2 10 and $100 \mathrm{ng} \mathrm{mL}^{-1}$ on proliferation is shown in Figure S6 (Supporting Information). After 7 days, cell culture was confluent, meaning that the surface was completely covered by cells forming a monolayer, and no difference could be distinguished between the MTF functionalized with hrBMP-2 and the bare MTF control. In Figure 7, we can observe that within the first day cells proliferated at the same rate and cell density was the same for the four evaluated substrates. After 2 days of culture, substrates with $100 \mathrm{ng} \mathrm{mL} \mathrm{mL}^{-1}$ of hrBMP-2 showed an enhanced cell proliferation rate if compared with cultures on MTFs and MTF with $10 \mathrm{ng} \mathrm{mL} \mathrm{m}^{-1}$ hrBMP-2 $(p<0.05) .{ }^{[54]}$ After 4 days of culture, same differences were maintained, but cell density was also higher when hrBMP-2 concentration is low (10 $\mathrm{ng} \mathrm{mL} \mathrm{mL}^{-1}$ ) if compared with bare MTFs. As previously seen in Figure S5 (Supporting Information), cells were more expanded and showing higher filopodia in presence of hrBMP-2. When the interaction of the cell with the substrate is better, it is known that proliferation is also improved. ${ }^{49,52]}$ 
$2 \mathrm{~h}$
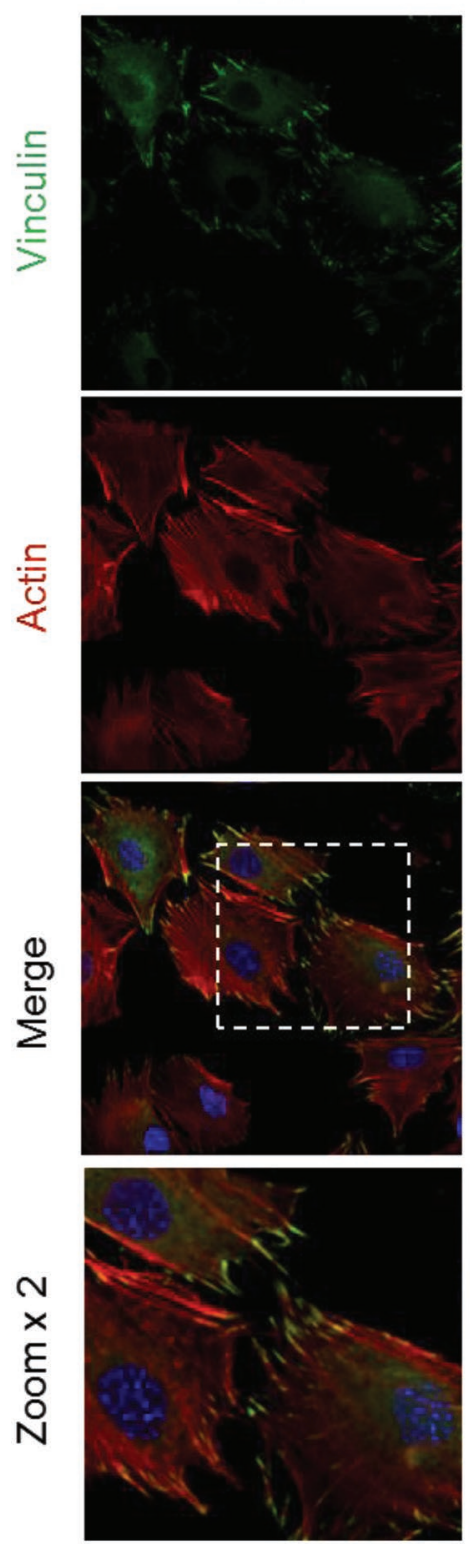

$24 \mathrm{~h}$
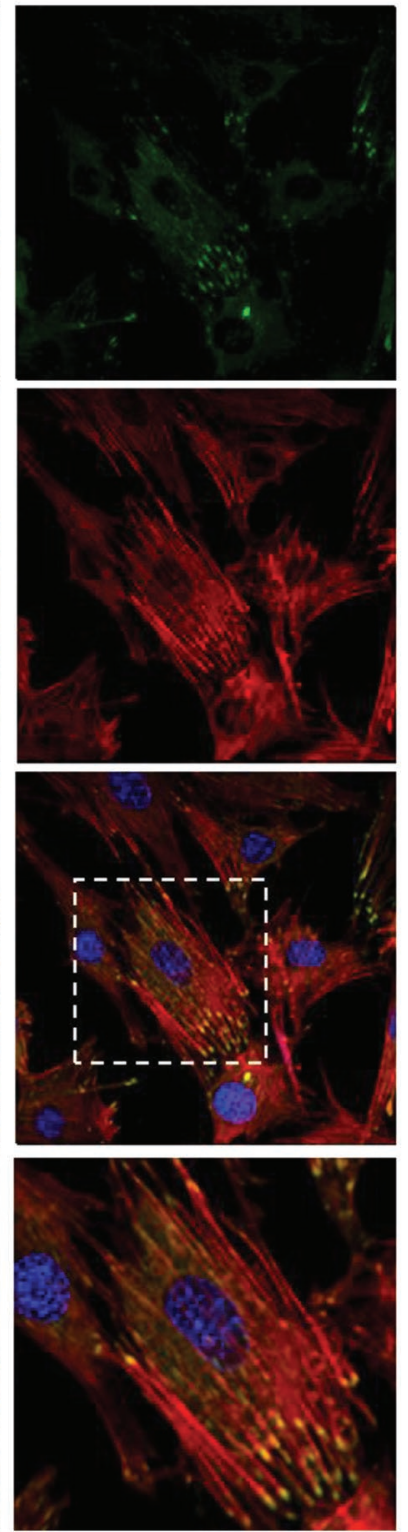

$48 \mathrm{~h}$
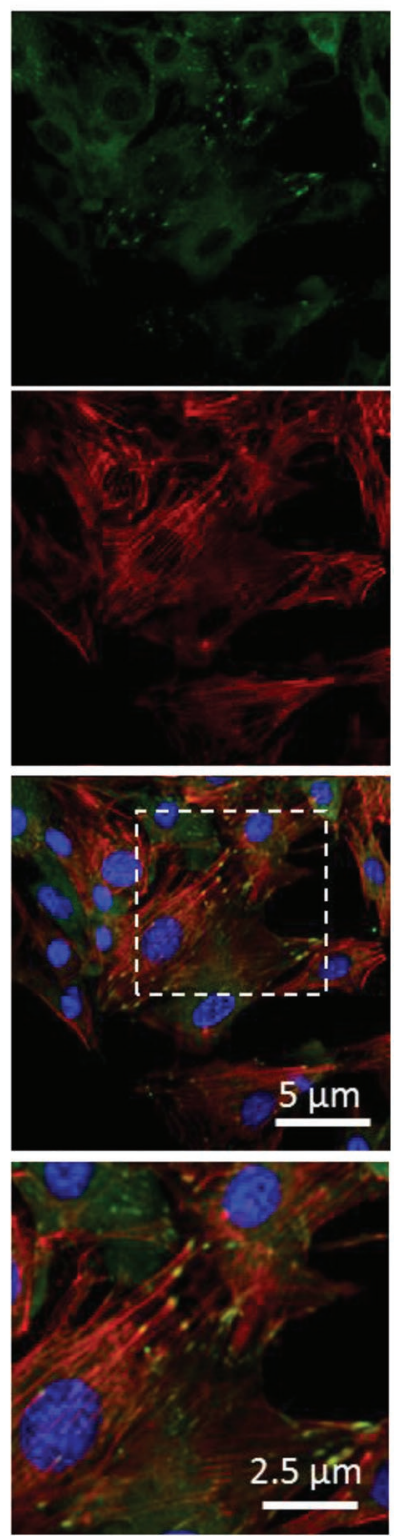

Figure 6. CLSM images of vinculin (first row), actin (second row), the merge of the actin, the vinculin, and the nucleus (third row) and the zoom of the merge image (fourth row) at $2 \mathrm{~h}$ (first column), $24 \mathrm{~h}$ (second column), and $48 \mathrm{~h}$ (third column) of growth of MC3T3-El cell line on MTF with hrBMP-2 $100 \mathrm{ng} \mathrm{mL}^{-1}$ and loaded with gentamicin at $63 \times$.

If MTFs were functionalized with gentamicin and hrBMP-2, if compared with films only functionalized with hrBMP-2, differences could be observed regarding the proliferation rates of MC3T3-E1 cells. At day 2, between samples with hrBMP-2 or samples with hrBMP-2 and loaded with gentamicin, there was no difference on cell density, and in both cases the density was higher than cell density on bare MTFs. If cells were cultured for 4 days, there was a difference between samples without and with gentamicin. After 4 days of cell culture, for the MTF with hrBMP-2 and loaded gentamicin, proliferation rate decreased in a $46 \%$, to values comparable to the proliferation observed for MTFs only loaded with gentamicin and for bare MTFs. The loading of the MTFs with gentamicin seems to cancel the positive action of hrBMP-2 on cell proliferation. Previous studies have shown that the interaction of gentamicin with channels and receptors in the cell membrane ${ }^{[55]}$ could lead to a decreased availability of the receptors of the BMP-2.

Alkaline phosphatase (AP) is one of the gene markers in the early stage of osteogenic differentiation. ${ }^{[56]}$ Figure 8 shows the AP activity of the cells cultured on MTFs, MTFs with hrBMP-2, and MTFs with hrBMP-2 and gentamicin. After cells reached confluence, they were differentiated for 20 days and AP activity was measured at different steps to evaluate differences in differentiation rates. At day 2 and day 5 of differentiation, there was no difference between the evaluated 


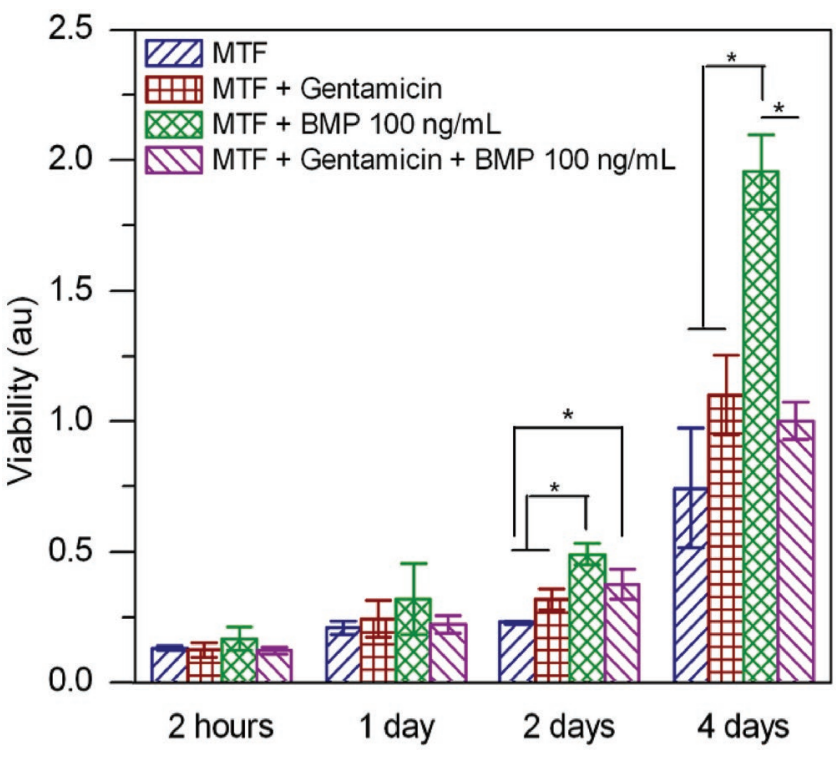

Figure 7. Proliferation of MC3T3-E1 preosteoblasts cultured on MTFs, MTFs with gentamicin, MTFs with hrBMP-2 $100 \mathrm{ng} \mathrm{mL}^{-1}$ and with hrBMP-2 $100 \mathrm{ng} \mathrm{mL}^{-1}$, and gentamicin substrates for $2 \mathrm{~h}$ and 1,2 , and 4 days. * means that the difference is statistically significant.

substrates and at day 20 all cells were differentiated and it was not possible to see any difference among substrates as well. Only at day 10 of cell culture in the differentiation medium, differences could be seen. For MTF coated with hrBMP-2, with or without gentamicin, the differentiation was more than double the differentiation on bare MTFs. This result was expected as the effectiveness of hrBMP-2 in promoting preosteoblast differentiation has been demonstrated in a large number of works. ${ }^{[57-60]}$

\subsection{Evaluation of the Antibacterial Properties of the hrBMP-2 and Gentamicin Functionalized MTFs}

The evaluation of the antibacterial capacity of MTFs loaded with gentamicin and hrBMP-2 functionalized was performed by incubating S. aureus for $24 \mathrm{~h}$ on top of the films.

Figure S7 (Supporting Information) shows colony-forming units (CFU) grown on the Luria-Bertani (LB) agar plates. Green ticks mean bacteria have grown on the agar plates and CFU counting is possible. Red crosses means that $S$. aureus have not grown on the LB agar plates. A total of $4.75 \times 10^{6} \pm 5.8 \times 10^{5}$ CFU are counted for MTF. In Figure 9a, a zoom of CFU grown on agar plates after growing in MTF is shown. However, when the MTF contains gentamicin, with or without hrBMP-2, bacteria were not grown, as can be seen in the zoom in Figure 9b. Figure 9c,d shows a cell observer image of $S$. aureus grown for $24 \mathrm{~h}$ on top of the MTF and the MTF functionalized with hrBMP-2 and gentamicin, respectively. The bare MTF surface was completely covered by the bacteria; the image shows black dots which are the coccus. The surface of the gentamicin loaded film shows very few dots; some bacteria become attached, but they are not alive, as seen in the agar plate culture, where no CFU were found.

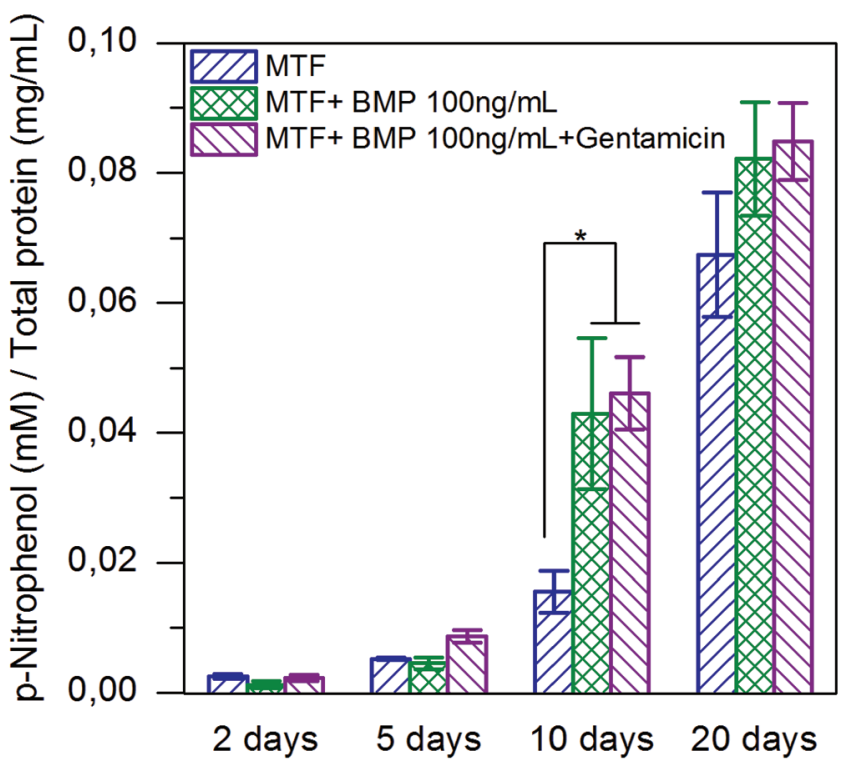

Figure 8. Alkaline phosphatase activity after 2, 5, 10, and 20 days of MC3T3-E1 preosteoblastic cell culture in osteogenic medium on MTF, MTF with hrBMP-2 $100 \mathrm{ng} \mathrm{mL}^{-1}$, and MTF with gentamicin and BMP $100 \mathrm{ng} \mathrm{mL}^{-1}$ substrates. * means the difference is statistically significant.

\section{Conclusion}

Highly mesoporous titania films with a $30.7 \%$ porous volume have been shown here to encapsulate gentamicin in the porous matrix to an extent that the films display antibacterial properties. At physiological $\mathrm{pH}$, the release of gentamicin in $10 \times 10^{-3}$ M PBS shows a two-step release profile. The porous structure of the titania results in an initial burst release of gentamicin within the first $6 \mathrm{~h}$ with a liberation of around the $36 \%$ of the total released gentamicin. The burst release is followed by a slow release of the remaining gentamicin that last over weeks. This release profile fits with the initial requirements of avoiding the formation of bacteria colonies on the implant while surgery is conducted releasing most of the gentamicin during first hour, while the rest of the gentamicin is released in lower doses for a period lasting weeks avoiding infection while the tissue is being reconstituted.

MTFs functionalized with hrBMP-2 improve MC3T3-E1 cell adhesion and proliferation. However, when the MTF is also loaded with gentamicin, proliferation rate is diminished but still is comparable to the proliferation rate for bare MTFs. Cell differentiation is not affected by the presence of gentamicin, and when MTFs are functionalized with hrBMP-2, the differentiation rate increases at day 10 to the double of the rate of cells cultured onto MTFs.

The efficacy of the functionalized substrates against S. aureus bacterial infection is shown seeding $1000 \mathrm{CFU}$ of bacteria on the gentamicin-loaded MTFs. Bacteria do not proliferate, hinting the potential of the gentamicin-loaded MFT for avoiding S. aureus infections.

Overall, our work shows the potential of mesoporous titania for antibiotic loading and delivery for avoiding bacterial infection. The release profile of gentamicin matches the requirement of a burst release during operation and immediately after 


\section{MTF}
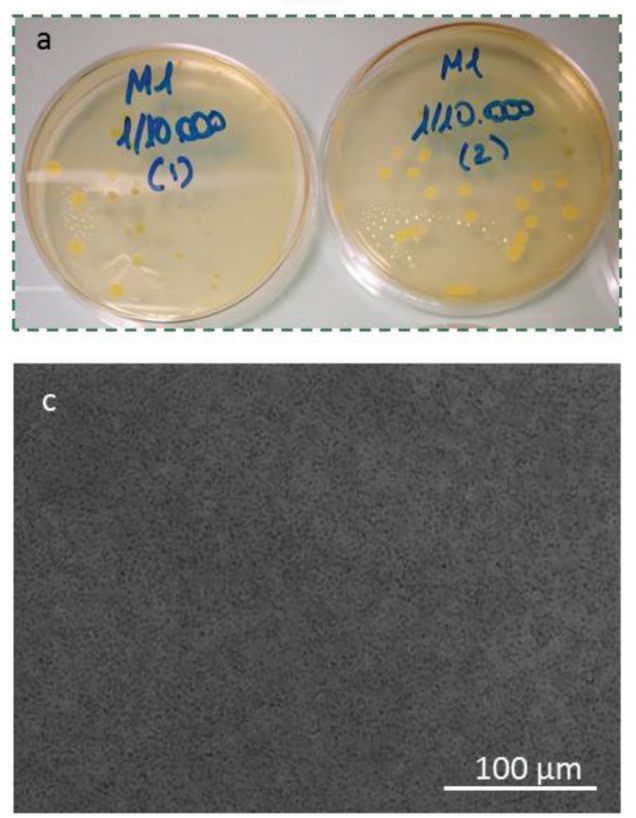

MTF + BMP $100 \mathrm{ng} / \mathrm{mL}+$ gentamicin

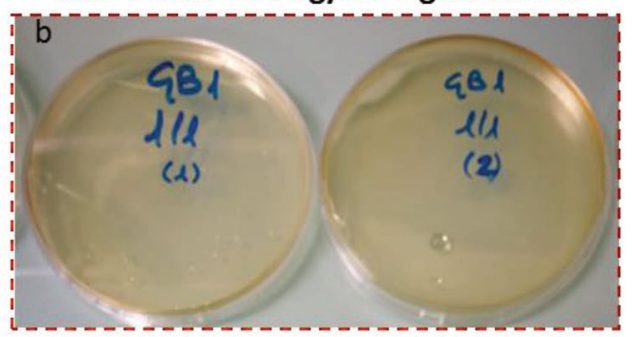

d

$100 \mu \mathrm{m}$

Figure 9. CFU counting after S. aureus growth on agar plates for $24 \mathrm{~h}$ and cell observer images of S. aureus growth on MTF and MTF functionalized with hrBMP-2 and gentamicin. a) Zoom of Sample 1 in Figure S6 (Supporting Information), agar plates with cultured S. aureus for $24 \mathrm{~h}$ on MTF in $1 / 10000$ dilution and b) zoom of Sample 1 in Figure S6 (Supporting Information), of agar plates with cultured S. aureus for $24 \mathrm{~h}$ on MTF with hrBMP-2 and gentamicin in 1/1 dilution. Cell observer images of $24 \mathrm{~h}$ of growth of S. aureus on c) MTF and d) MTF with hrBMP-2 and gentamicin substrates.

followed by a sustainable release of gentamicin until the bone tissue is reconstituted. The additional modification of the MTF with hrBMP-2 has a positive effect on proliferation and cell adhesion that seems to overcome negative effects from gentamicin on osteoblasts.

\section{Experimental Section}

Mesoporous Titania Film Synthesis and Characterization: Mesoporous titania films with a pore size of $5.7 \mathrm{~nm}$ were synthesized by sol-gel chemistry and the EISA method. Rounded glass slides with $14 \mathrm{~mm}$ diameter and $0.13-0.16 \mathrm{~mm}$ thickness from Thermo Fisher Scientific were used for film deposition. Pluronic F-127 (EO $\left.\mathrm{EO}_{106} \mathrm{PO}_{70} \mathrm{EO}_{106}\right)$ was used as a structure-directing agent.

For sol preparation, titanium(IV) chloride $\left(\geq 99.0 \%, \mathrm{TiCl}_{4}\right)$, ethanol absolute (Synthesis grade, EtOH), Pluronic F-127, and nanopure water $\left(\mathrm{H}_{2} \mathrm{O}\right)$ were mixed in a molar proportion of $\mathrm{TiCl}_{4}: \mathrm{EtOH}: \mathrm{F}-127: \mathrm{H}_{2} \mathrm{O}$ $=1: 40: 0.0056: 10$. The titania precursor was prepared first, adding $\mathrm{TiCl}_{4}$ to EtOH under vigorous stirring. When this solution was dropped to room temperature, the $\mathrm{F}-127$ and $\mathrm{H}_{2} \mathrm{O}$ were added and left stirring for $10 \mathrm{~min}$ to obtain a homogeneous solution. All the reagents were purchased from Sigma Aldrich except for the ethanol, purchased from Scharlau.

To produce uniform films, $30 \mu \mathrm{L}$ of the sol, previously mixed with $\mathrm{EtOH}$ in a volume proportion of sol: $\mathrm{EtOH}=2: 1$, was spin-coated at $68 \mathrm{rpm}$ for $30 \mathrm{~s}$ in the glass slices using a SCC-200 spin coater from Novocontrol Technologies. Taking advantage of EISA ${ }^{[61]}$ after the sol deposition, films were placed for $30 \mathrm{~min}$ in a humidity chamber with a controlled relative humidity of $50 \%$, obtained with saturated calcium nitrate $\left(\mathrm{Ca}\left(\mathrm{NO}_{3}\right)_{2}\right)$ solution in water. Then, they were subjected to a gentle thermal treatment: $30 \mathrm{~min}$ at $60^{\circ} \mathrm{C}$ and another $30 \mathrm{~min}$ at $130^{\circ} \mathrm{C}$. Finally, they were calcined; first, heating up with a ramp of $1{ }^{\circ} \mathrm{C} \mathrm{min}^{-1}$ and then keeping them at $350^{\circ} \mathrm{C}$ for $2 \mathrm{~h}$.
For pore visualization, a JEOL JEM-1400PLUS transmission electron microscope equipped with a Gatan US1000 CCD camera was used. Films were scratched to obtain a powder, which was deposited on carbonated copper grids with a drop of pure ethanol. Film topography was visualized with a field emission scanning electron microscopy (FE-SEM) Carl Zeiss NTS Supra 40 at the Advanced Microscopy Center FCEN-UBA.

Ellipsometric and EEP measurements of MTFs were performed in a SOPRA GES5A ellipsometer, using samples previously washed with absolute ethanol and dried. Film thickness and refractive index values were obtained from the ellipsometric parameters $\Psi$ and $\Delta$ under dry air flux containing variable water vapor pressure $P ; P / P_{0}$ was varied from 0 to $1\left(P_{0}\right.$ being the saturation water vapor pressure at $\left.25^{\circ} \mathrm{C}\right)$. Water volume adsorbed at each $P / P_{0}$ value was determined by modeling the obtained refractive index according to a three-component (water-air-oxide) Bruggeman effective medium approximation. Adsorption-desorption isotherms were obtained by plotting the water volume adsorbed by the porous film at each $P / P_{0}$. The pore size distribution was obtained from the isotherms using the Kelvin equation, taking into account the water contact angle in the film. ${ }^{[62]}$ Water contact angles required for such calculations were determined using a Ramé-Hart 190 CA equipment.

Prior to its use, MTFs were cleaned as follows; they were immersed in absolute ethanol for $30 \mathrm{~min}, 15 \mathrm{~min}$ in distilled water, dried with $\mathrm{N}_{2}$ gun, and sterilized for $1 \mathrm{~h}$ under UV light.

2D-SAXS patterns were obtained at the Austrian SAXS beamline at the Elettra synchrotron (Trieste, Italy), using a $1.54 \AA$ ( $8 \mathrm{keV}$ ) incidence $X$-ray beam. The sample was placed at $82.88 \mathrm{~cm}$ from a pixel detector (Pilatus $1 \mathrm{M}$ ) on a rotation stage, which was allowed to set the glancing angle between the incident radiation and the sample to $3^{\circ} .^{[63]}$ The samples were prepared onto coverslips to allow measurements in Laue geometry. The angular scale of the detector was calibrated with $\mathrm{Ag}$ behenate as the reference pattern.

Nanomechanical tests were performed using a triboindenter (Hysitron-TI-950), equipped with a Berkovich tip and a 2D-axis transducer. The value of the elastic modulus (Er) was extracted from 
nanoindentation tests. Indentation measurements were performed ten times using partial load-unload function and the Oliver-Pharr method ${ }^{[64]}$ and then corrected following the method described by Coy et al. ${ }^{[65]}$ Measurements were performed after $120 \mathrm{~s}$ of drift correction and shallow calibration $(5-30 \mathrm{~nm})$ of the indenter on commercially available fused quartz $(69.6 \mathrm{CPa})$.

Deposition of Bone Morphogenetic Protein 2: A drop of $100 \mu \mathrm{L}$ of human recombinant bone morphogenetic protein 2 (Sigma Aldrich) at concentrations of 10, 100, and $1000 \mathrm{ng} \mathrm{mL}^{-1}$ in PBS (Sigma Aldrich) $\left(10 \times 10^{-3} \mathrm{M}\right)$ was left adsorbing for $1 \mathrm{~h}$ on top of MTFs.

Water contact angles were measured for hrBMP-2 adsorbed on MTFs and gentamicin loading using Drop Shape Analyzer-DSA100 Kruss equipment. Three different films measured.

The presence of sulfur after hrBMP-2 immobilization and gentamicin loading was confirmed by XPS atomic composition analysis. A SPECS Sage HR 100 spectrometer equipped with a $100 \mathrm{~mm}$ mean radius PHOIBOS analyzer and a non-monochromatic X-ray source $(\mathrm{Mg} \mathrm{K} \alpha$ line of $1253.6 \mathrm{eV}$ energy and $250 \mathrm{~W}$ ), placed perpendicular to the analyzer axis and calibrated using the $3 d_{5 / 2}$ line of $\mathrm{Ag}$, with a full width at half maximum of $1.1 \mathrm{eV}$ was used. The selected resolution for high resolution spectra was $15 \mathrm{eV}$ of pass energy and $0.15 \mathrm{eV}$ per step. All measurements were made in an ultrahigh vacuum chamber at a pressure of around $8 \times 10^{-8} \mathrm{mbar}$. An electron flood gun was used to neutralize for charging. Measurements were conducted directly on the films, which were previously washed with absolute ethanol. The analysis of spectra was done with CasaXPS 2.3.15dev87 software. Satellite removal and Shirley background subtraction were applied. Binding energies were calibrated assigning to the $\mathrm{C} 1 \mathrm{~s} \mathrm{C}-\mathrm{C}$ peak $285 \mathrm{eV}$, and peaks were fitted with Gaussian-Lorentzian line shapes. The MTF exposed to the lowest hrBMP-2 concentration ( $10 \mathrm{ng} \mathrm{mL}^{-1}$ ) was used for XPS characterization.

AFM images of samples without any functionalization, functionalized with hrBMP-2 $100 \mathrm{ng} \mathrm{mL}^{-1}$ and MTFs functionalized with $100 \mathrm{ng} \mathrm{mL}^{-1}$ hrBMP-2 and loaded with gentamicin were obtained with a Nanowizard II AFM (JPK, Berlin, Germany). Images were produced in air in tapping mode using the tip TESP-V2 (Bruker, AFM probes) which had a spring constant of $40 \mathrm{~N} \mathrm{~m}^{-1}$ and a resonant frequency in the range of $280-320 \mathrm{kHz}$. Average roughness $R_{\mathrm{a}}$ was calculated, which gives the deviation in height. ${ }^{[66-68]}$

Gentamicin Loading and Release: Gentamicin sulfate salt was purchased from Sigma Aldrich. For gentamicin loading, MTFs were immersed for $24 \mathrm{~h}$ in a $0.2 \mathrm{mg} \mathrm{mL}^{-1}$ gentamicin solution in distilled water. For films functionalized with hrBMP-2, gentamicin was loaded after the adsorption of the growth factor. To remove gentamicin deposited on top of the MTFs and not in the pores, MTFs were immersed once in distilled water prior to their use.

O-phthaldialdehyde (OPA) reagent was used to study the gentamicin release. ${ }^{[69,70]}$ Boric acid was dissolved in distilled water to obtain a concentration of $0.4 \mathrm{M}$ and $\mathrm{pH}$ was adjusted to 10.4 with potassium hydroxide solution. OPA reagent was prepared according to the following procedure: $0.2 \mathrm{~g}$ of OPA was dissolved in $1 \mathrm{~mL}$ of methanol and the solution was mixed with $19 \mathrm{~mL}$ of a $0.4 \mathrm{M}$ boric buffer. Then, $0.4 \mathrm{~mL}$ of 2-mercaptoethanol was added and the $\mathrm{pH}$ was adjusted to 10.4 with the potassium hydroxide solution. This reagent was kept in the dark at $4{ }^{\circ} \mathrm{C}$ until its use in the following day. Samples and the 2-propanol were mixed in 1:1 proportion in volume and vortexed. Then, the OPA reagent was added in the same proportion and the solution was vortexed again. ${ }^{[69,70]}$ For $15 \mathrm{~min}$, prior to measurement, the solutions were heated at $60{ }^{\circ} \mathrm{C}$ to catalyze the reaction. All the reagents were purchased from Sigma Aldrich, except 2-propanol, which was obtained from Fisher.

Gentamicin release was studied by placing the loaded MTFs in a 24 multiwell dish. $1 \mathrm{~mL}$ of $10 \times 10^{-3} \mathrm{M}$ PBS was added to the wells with the sample. The release was measured at 15 and $30 \mathrm{~min}$, at 1, 2, 4 , and $6 \mathrm{~h}$, and at $2,3,6,7,10,21,28$, and 35 days. PBS solution was removed for each measurement from the well and replaced with fresh PBS. Gentamicin calibration curve was performed with concentrations of gentamicin ranging from 0 to $2 \mu \mathrm{g} \mathrm{mL} \mathrm{L}^{-1}$ containing seven points. The calibration curve can be described with the following equation: $\gamma=6.49$ $+21.26 x$, where $y$ is the emission of the OPA-gentamicin complex at
$450 \mathrm{~nm}$ and $x$ is the gentamicin concentration in $\mu \mathrm{g} \mathrm{mL}^{-1}$ and has an $R^{2}$ of 0.997 .

The fluorescent complex of gentamicin with OPA has its maximum absorption at $340 \mathrm{~nm}$ and the emission at $450 \mathrm{~nm}$. Fluorescence was collected at a Thermo Scientific Varioskan Flash Multimode Reader.

S. aureus Culture and Antimicrobial Susceptibility Assay: S. aureus is Gram-positive spherical bacteria and the RN4220 strain used in this work is resistant to erythromycin. It was cultured in LB broth from Lennox with $10 \mu \mathrm{g} \mathrm{mL} \mathrm{L}^{-1}$ erythromycin overnight at $37^{\circ} \mathrm{C}$ under constant shaking at $200 \mathrm{rpm}$.

After $24 \mathrm{~h}$ of growth in LB Broth, the bacteria were centrifuged at $2500 \mathrm{rpm}$ for $5 \mathrm{~min}$ and washed in $10 \times 10^{-3} \mathrm{M}$ PBS with $150 \times 10^{-3} \mathrm{M}$ $\mathrm{NaCl}\left(\mathrm{pH}\right.$ 7.4) three times. They were resuspended in $10 \times 10^{-3} \mathrm{M}$ PBS and optical density was adjusted to 0.257 at $600 \mathrm{~nm}$ with an UV-VIS Varian Cary 50 spectrophotometer, estimated to give $3 \times 10^{8} \mathrm{CFU}$ per milliliter. The bacteria solution was diluted in LB Broth with $10 \mu \mathrm{g} \mathrm{mL}^{-1}$ erythromycin (Sigma Aldrich). Films were added into 24 multiwell dishes and $1 \mathrm{~mL}$ of LB Broth containing $1000 \mathrm{CFU}$ was added on top of the films and incubated for $24 \mathrm{~h}$ at $37^{\circ} \mathrm{C}$. Then, the media was removed and samples were removed from the wells. To detach the adhered bacteria, samples were vortexed at $30000 \mathrm{rpm}$ for 1 min inside sterile $50 \mathrm{~mL}$ centrifuge tubes with $10 \mathrm{~mL}$ of $10 \times 10^{-3} \mathrm{M}$ PBS. Three dilutions were performed in PBS to culture $100 \mu \mathrm{L}$ onto sterile LB Agar (Lennox) with $10 \mu \mathrm{g} \mathrm{mL} \mathrm{m}^{-1}$ erythromycin. Bacteria were diluted in $1 / 1,1 / 10$, and $1 / 100$ for films containing gentamicin and for bare MTF control dilutions were $1 / 10000,1 / 100000$, and $1 / 1000000$, respectively. Plates were placed into an incubator at $37^{\circ} \mathrm{C}$ to allow colonies to grow until visual counting was possible $(\approx 24 \mathrm{~h})$.

Cell Culture, Adhesion, Proliferation, and Differentiation: The MC3T3-E1 preosteoblastic cell line was purchased from Sigma Aldrich. Preosteoblasts were maintained in alpha minimum essential medium $(\alpha$-MEM) containing 10\% fetal bovine serum (FBS), 1\% penicillinstreptomycin, and $2 \times 10^{-3} \mathrm{M} \mathrm{L-glutamine.} \mathrm{They} \mathrm{were} \mathrm{subcultured} \mathrm{every}$ 3 days until passage 40 . For cell differentiation, the previous medium was supplemented with $50 \mu \mathrm{g} \mathrm{mL} \mathrm{L}^{-1} \mathrm{~L}$-ascorbic acid, and $2 \times 10^{-3} \mathrm{M}$ $\beta$-glycerophosphate. All the reagents were purchased from Sigma Aldrich.

MTFs were sterilized for $1 \mathrm{~h}$ under UV light. The solutions containing the hrBMP-2 and gentamicin were filtered with $0.22 \mu \mathrm{m}$ filters prior to their use, inside the biosecurity 2 chamber. All the substrates were prepared under sterile condition prior to their use for cell culture experiment.

To confirm cell adhesion to the substrates confocal laser scanning microscopy (Zeiss LSM510), observations were performed after F-actin, focal adhesions, and nucleus labeling with actin cytoskeleton and focal adhesion staining kit (FAK100, Millipore). Briefly, after reaching the $80 \%$ confluence, cells were trypsinized and resuspended in fresh medium to a final cell density of $3 \times 10^{4}$ cells $\mathrm{mL}^{-1}$. About $1 \mathrm{~mL}$ of cell suspension was added into each well of 24 multiwell cell culture plates with MTFs, gentamicin loaded MTFs, hrBMP-2 functionalized MTFs, and hrBMP-2 functionalized MTFs loaded with gentamicin. After culturing for $2 \mathrm{~h}$, $24 \mathrm{~h}, 48 \mathrm{~h}$, and 7 days, cells were fixed with a $4 \%$ paraformaldehyde solution. Cells were first permeabilized with $0.1 \%$ Triton-X100 (Sigma Aldrich) for $4 \mathrm{~min}$ at room temperature. Then, cells were incubated in dilute antivinculin primary antibody for $1 \mathrm{~h}$ at room temperature, followed by three times wash for 5-10 min each with wash buffer (PBS with $0.05 \%$ Tween-20 (Sigma Aldrich)), followed by $1 \mathrm{~h}$ further incubation with an FITC-conjugated secondary antibody and tetramethylrhodamine (TRITC)-conjugated Phalloidin at room temperature. After three times rinsing with wash buffer, cells were incubated with DAPI for $3 \mathrm{~min}$ at room temperature, followed by a three time wash.

Cell proliferation colorimetric analysis was performed with the Cell Counting Kit-8 (CCK-8) (Sigma Aldrich) containing WST-8 [2-(2-methoxy4-nitrophenyl)-3-(4-nitrophenyl)-5-(2,4-disulfophenyl)-2H-tetrazolium, monosodium salt], a nontoxic dye used for continuous cell culturing. When cells reached $80 \%$ confluence, they were trypsinized and resuspended in fresh medium to a final cell density of $3 \times 10^{4}$ cells $\mathrm{mL}^{-1}$. $1 \mathrm{~mL}$ of cell suspension was added into each well of 24 multiwell cell culture plates with the functionalized MTFs inside. Cells cultured 
on the films were refreshed with $250 \mu \mathrm{L} 10 \% \mathrm{v} / \mathrm{v}$ of CCK-8 containing medium, and after $2 \mathrm{~h}$ of incubation at $37^{\circ} \mathrm{C}$ two aliquots of $100 \mu \mathrm{L}$ of each sample were placed into a 96 -well cell plate. The absorbance was measured using a plate reader (GENios Pro, Tecan) equipped with a $450 \mathrm{~nm}$ filter. Measurements were done by triplicate at $2 \mathrm{~h}, 24 \mathrm{~h}, 48 \mathrm{~h}$, and 7 days.

Proliferating osteoblasts show AP activity in the stage of extracellular matrix maturation, being greatly enhanced during in vitro bone formation. AP activity is therefore a feasible marker for differentiating and mineralizing osteoblastic formation. ${ }^{[71]}$ For AP quantification, $1 \mathrm{~mL}$ of cells was seeded with a density of $5 \times 10^{4} \mathrm{cell} \mathrm{mL}^{-1}$ in a 24 multiwell dish. After 4 days of growth, cells were cultured in osteogenic medium for 20 days following the differentiation during this time.

AP was quantified with the StemTAG Alkaline Phosphatase Activity Assay Kit from Cell Biolabs Inc. The AP catalyzes the conversion of $\mathrm{p}$-nitrophenyl phosphate (pNPP) to $\mathrm{p}$-nitrophenol ( $\mathrm{pN})$. $\mathrm{pN}$ is a bright yellow-colored compound which has maximum absorbance at $405 \mathrm{~nm}$. The rate of increase in absorbance from pNPP (colorless) to $\mathrm{pN}$ (color) is directly proportional to the AP enzyme activity in the serum sample. Following the indications of the fabricant, a calibration curve with $\mathrm{pN}$ at concentrations ranging from $0.5 \times 10^{-3}$ to $0.9766 \times 10^{-6} \mathrm{M}$ was performed. The calibration curve to determine the total amount of $\mathrm{pN}$ was obtained from ten points and is $y=0.044+7.51 x$, where $y$ is the absorbance at $405 \mathrm{~nm}$ and $x$ is the $\mathrm{pN}$ concentration in $\left(\times 10^{-3}\right) \mathrm{M}$ with an $R^{2}$ of 0.999 . Cells were cleaned twice with cold PBS and lysated with $250 \mu \mathrm{L}$ lysis buffer for $10 \mathrm{~min}$ at $4{ }^{\circ} \mathrm{C}$. Lysated cells have to be spin down at $12.000 \times \mathrm{g}$ for $10 \mathrm{~min}$ and the supernatant must be kept. 1:1 relation in volume of cell lysate and pNPP were incubated for $15 \mathrm{~min}$ at $37^{\circ} \mathrm{C}$. To stop the reaction, the same proportion in volume of stop solution was added and shaked for $30 \mathrm{~s}$.

The Bradford assay was carried out to quantify the protein in the lysate and normalize the results. One part of the protein sample was mixed with 30 parts of the Bradford Reagent, which consists of a dye, Brilliant Blue $G$ that forms a complex with proteins, shifting the absorption maximum from 465 to $595 \mathrm{~nm}$. Bovine serum albumin (BSA, Sigma Aldrich) was used as standard protein. The calibration curve with five points ranging from 1 to $2 \mathrm{mg} \mathrm{mL}^{-1}$ of BSA is $=0.37+0.13 x$, where $y$ is the absorbance at $595 \mathrm{~nm}$ and $x$ is the total amount of protein in $\mathrm{mg} \mathrm{mL}^{-1}$ with an $R^{2}$ of 0.983 . Absorbance measurements were performed at a Thermo Scientific Varioskan Flash Multimode Reader.

All the statistical analysis concerning analysis of variance (ANOVA) was done using OriginPro 2016 software. Fisher's tests were performed to determine statistically significant differences with $p<0.05$.

\section{Supporting Information}

Supporting Information is available from the Wiley Online Library or from the author.

\section{Acknowledgements}

G.C.W. would like to acknowledge funding support from Shenzhen Science and Technology Research funding (JCYJ20170413161800287) and Guangdong Provincial Science and Technology Project (2017A010103014 and 2018A030313015). The authors thank the project MAT2017-88752-R from the ministerio de economia y competitividad, gobierno de España. This work was performed under the Maria de Maeztu Units of Excellence Program from the Spanish State Research Agency-Grant No. MDM2017-0720. The authors thank Dr. Andrey Chuvilin for the help with SEM images and Dr. Julia Cope for revising the manuscript.

\section{Conflict of Interest}

The authors declare no conflict of interest.

\section{Keywords}

bone morphogenetic protein 2, gentamicin, mesoporous titania films, preosteoblasts, Staphylococcus aureus

Received: October 19, 2018

Revised: January 31, 2019

Published online:

[1] M. Navarro, A. Michiardi, O. Castano, J. Planell, J. R. Soc., Interface 2008, 5, 1137

[2] K. R. Smith, T. R. Hunt, M. A. Asher, H. C. Anderson, W. L. Carson, R. G. Robinson, J. Bone Jt. Surg. 1991, 73, 115.

[3] M. Z. Ibrahim, A. A. D. Sarhan, F. Yusuf, M. Hamdi, J. Alloys Compd. 2017, 714, 636.

[4] L. C. Jones, L. D. Timmie Topoleski, A. K. Tsao, in Mechanical Testing of Orthopaedic Implants (Ed: E. Friis), Woodhead Publishing, Sawston, UK 2017, p. 17.

[5] D. Campoccia, L. Montanaro, C. R. Arciola, Biomaterials 2006, 27, 2331.

[6] Z. Song, L. Borgwardt, N. Høiby, H. Wu, T. S. Sørensen, A. Borgwardt, Orthop. Rev. 2013, 5, 14.

[7] E. Barth, Q. M. Myrvik, W. Wagner, A. G. Gristina, Biomaterials 1989, 10, 325.

[8] C. von Eiff, R. A. Proctor, G. Peters, Postgrad. Med. 2001, 110, 63.

[9] F. D. Lowy, N. Engl. J. Med. 1998, 339, 520.

[10] S. D. Elek, Ann. N. Y. Acad. Sci. 1956, 65, 85.

[11] D. Li, P. Lv, L. Fan, Y. Huang, F. Yang, X. Mei, D. Wu, Biomater. Sci. 2017, 5, 2337.

[12] L. Séon, P. Lavalle, P. Schaaf, F. Boulmedais, Langmuir 2015, 31, 12856.

[13] K. Yang, Q. Han, B. Chen, Y. Zheng, K. Zhang, Q. Li, J. Wang, Int. J. Nanomed. 2018, 13, 2217.

[14] W. Zhou, Z. Jia, P. Xiong, J. Yan, M. Li, Y. Cheng, Y. Zheng, Mater. Sci. Eng., C 2018, 90, 693.

[15] L. Montanaro, D. Campoccia, C. R. Arciola, Int. J. Artif. Organs 2008, 31, 771 .

[16] A. S. K. Kiran, T. S. Sampath Kumar, G. Perumal, R. Sanghavi, M. Doble, S. Ramakrishna, Prog. Org. Coat. 2018, 121, 112.

[17] S. Spriano, S. Yamaguchi, F. Baino, S. Ferraris, Acta Biomater. 2018, 79, 1.

[18] M. Geetha, A. K. Singh, R. Asokamani, A. K. Gogia, Prog. Mater. Sci. 2009, 54, 397

[19] J. Lawrence Katz, Nature 1980, 288, 196.

[20] M. Del Fabbro, S. Taschieri, E. Canciani, A. Addis, F. Musto, R. Weinstein, C. Dellavia, Implant Dent. 2017, 26, 357.

[21] K. Karthik, Sivakumar, Sivaraj, V. Thangaswamy, J. Pharm. BioAllied Sci. 2013, 5, 117.

[22] V. Secchi, S. Franchi, M. Santi, A. Vladescu, M. Braic, T. Skála, J. Nováková, M. Dettin, A. Zamuner, G. Iucci, C. Battocchio, V. Secchi, S. Franchi, M. Santi, A. Vladescu, M. Braic, T. Skála, J. Nováková, M. Dettin, A. Zamuner, G. Iucci, C. Battocchio, Nanomaterials 2018, 8, 148.

[23] B. D. Boyan, E. M. Lotz, Z. Schwartz, Tissue Eng., Part A 2017, 23, 1479.

[24] F. Bayata, C. Yildiz, Adv. Mater. Sci. Eng. 2018, 2018, 5047319.

[25] Z. Q. Yao, Y. Ivanisenko, T. Diemant, A. Caron, A. Chuvilin, J. Z. Jiang, R. Z. Valiev, M. Qi, H.-J. Fecht, Acta Biomater. 2010, 6, 2816.

[26] C. N. Elias, J. H. C. Lima, R. Valiev, M. A. Meyers, JOM 2008, 60, 46.

[27] E. Avcu, Y. Yıldıran Avcu, F. E. Baştan, M. A. U. Rehman, F. Üstel, A. R. Boccaccini, Prog. Org. Coat. 2018, 123, 362.

[28] M. Vallet-Regí, M. Manzano Garcia, M. Colilla, Biomedical Applications of Mesoporous Ceramics: Drug Delivery, Smart Materials and Bone Tissue Engineering, CRC Press, Boca Raton, FL 2012. 
[29] L. Zhou, X. Zheng, Z. Gu, W. Yin, X. Zhang, L. Ruan, Y. Yang, Z. Hu, Y. Zhao, Biomaterials 2014, 35, 7666.

[30] M. Vallet-Regí, F. Balas, D. Arcos, Angew. Chem., Int. Ed. 2007, 46, 7548

[31] K. C.-W. Wu, Y. Yamauchi, J. Mater. Chem. 2012, 22, 1251.

[32] J. L. Vivero-Escoto, Y.-D. Chiang, K. Wu, Y. Yamauchi, Sci. Technol. Adv. Mater. 2012, 13, 013003.

[33] Y. Yamauchi, J. Ceram. Soc. Jpn. 2013, 121, 831.

[34] S. Chen, Y. Zhu, W. Li, W. Liu, L. Li, Z. Yang, C. Liu, W. Yao, X. Lu, X. Feng, Chin. J. Catal. 2010, 31, 605.

[35] Z. Luo, Y. Hu, K. Cai, X. Ding, Q. Zhang, M. Li, X. Ma, B. Zhang, Y. Zeng, P. Li, J. Li, J. Liu, Y. Zhao, Biomaterials 2014, 35, 7951.

[36] T. Rahman, R. Liu, E. Ortel, R. Kraehnert, A. Antoniou, Appl. Phys. Lett. 2014, 104, 241902.

[37] H. Qu, S. Bhattacharyya, P. Ducheyne, in Comprehensive Biomaterials, Vol. 4 (Ed: P. Ducheyne), Elsevier, Amsterdam, Netherlands 2011, p. 475.

[38] C. A. Stewart, Y. Finer, B. D. Hatton, Sci. Rep. 2018, 8, 895.

[39] S. Atefyekta, B. Ercan, J. Karlsson, E. Taylor, S. Chung, T. J. Webster, M. Andersson, Int. J. Nanomed. 2016, 11, 977.

[40] S. Zhang, X. Cheng, J. Shi, J. Pang, Z. Wang, W. Shi, F. Liu, B. Ji, Int. J. Electrochem. Sci. 2018, 13, 4046.

[41] M. K. Pierchala, M. Makaremi, H. L. Tan, J. Pushpamalar, S. Muniyandy, A. Solouk, S. M. Lee, P. Pasbakhsh, Appl. Clay Sci. 2018, 160, 95

[42] M. E. Butini, S. Cabric, A. Trampuz, M. Di Luca, Colloids Surf., B 2018, 161, 252.

[43] G.-J. A. Ter Boo, T. Schmid, I. Zderic, D. Nehrbass, K. Camenisch, R. G. Richards, D. W. Grijpma, T. F. Moriarty, D. Eglin, Eur. Cells Mater. 2018, 35, 151.

[44] A. Escobar, L. Yate, M. Grzelczak, H. Amenitsch, S. E. Moya, A. V Bordoni, P. C. Angelome, ACS Omega 2017, 2, 4548.

[45] D. F. Lionello, P. Y. Steinberg, M. M. Zalduendo, G. J. de A. A. Soler-Illia, P. C. Angelomé, M. C. Fuertes, J. Phys. Chem. C 2017, 121, 22576.

[46] Y. Gaillard, V. J. Rico, E. Jimenez-Pique, A. R. González-Elipe, J. Phys. D: Appl. Phys. 2009, 42, 145305.

[47] J. M. Anderson, Annu. Rev. Mater. Res. 2001, 31, 81.

[48] P. C. Angelomé, G. J. de A. A. Soler-Illia, Chem. Mater. 2005, 17, 322.
[49] K. Anselme, Biomaterials 2000, 21, 667.

[50] Z. Zhang, B. Gu, W. Zhu, L. Zhu, Exp. Ther. Med. 2013, 6, 707.

[51] S. H. Gong, H. Lee, A. Pae, K. Noh, Y. M. Shin, J. H. Lee, Y. H. Woo, J. Adv. Prosthodontics 2013, 5, 416.

[52] K. A. DeMali, Trends Biochem. Sci. 2004, 29, 565.

[53] J. D. Humphries, P. Wang, C. Streuli, B. Geiger, M. J. Humphries, C. Ballestrem, J. Cell Biol. 2007, 179, 1043.

[54] C. Fu, X. Yang, S. Tan, L. Song, Sci. Rep. 2017, 7, 12549.

[55] E. Kovács, T. Savopol, M.-M. Iordache, L. Săplăcan, I. Sobaru, C. Istrate, M.-P. Mingeot-Leclercq, M.-G. Moisescu, Bioelectrochemistry 2012, 87, 230.

[56] M. Murshed, D. Harmey, J. L. Millán, M. D. McKee, G. Karsenty, Genes Dev. 2005, 19, 1093.

[57] E. Hunziker, J. Jovanovic, A. Horner, M. Keel, K. Lippuner, N. Shintani, Eur. Cells Mater. 2016, 32, 241.

[58] J. de Queiroz Fernandes, V. N. de Lima, J. P. Bonardi, O. M. Filho, S. B. F. Queiroz, J. Maxillofac. Oral Surg. 2018, 17, 13.

[59] S. Sun, Y. Zhang, D. Zeng, S. Zhang, F. Zhang, W. Yu, J. Mater. Sci.: Mater. Med. 2018, 29, 141.

[60] M. Lingner, R. Seidling, L. J. Lehmann, E. Mauermann, U. Obertacke, M. L. R. Schwarz, J. Orthop. Surg. Res. 2018, 13, 219.

[61] J. Brinker, Y. Lu, A. Sellinger, H. Fan, Adv. Mater. 1999, 11, 579.

[62] C. Boissiere, D. Grosso, S. Lepoutre, L. Nicole, A. Aline Brunet Bruneau, C. Sanchez, Langmuir 2005, 21, 12362.

[63] H. Amenitsch, S. Bernstorff, M. Kriechbaum, D. Lombardo, H. Mio, M. Rappolt, P. Laggner, J. Appl. Crystallogr. 1997, 30, 872.

[64] W. C. Oliver, G. M. Pharr, J. Mater. Res. 1992, 7, 1564.

[65] E. Coy, L. Yate, Z. Kabacińska, M. Jancelewicz, S. Jurga, I. Iatsunskyi, Mater. Des. 2016, 111, 584.

[66] M. Raposo, Q. Ferreira, P. A. Ribeiro, in Modern Research and Educational Topics in Microscopy, Vol. 2 (Eds: A. Méndez-Vilas, J. Díaz), Formatex Research Center, Badajoz, Spain 2007, p. 758.

[67] Z. Ye, X. Zhao, J. Microsc. 2010, 238, 27.

[68] S. N. Magonov, V. Elings, M.-H. Whangbo, Surf. Sci. Lett. 1997, 375, L385.

[69] J. Krzek, H. Woltyńska, U. Hubicka, Anal. Lett. 2009, 42, 473.

[70] J. Gubernator, Z. Drulis-Kawa, A. Kozubek, Int. J. Pharm. 2006, 327, 104.

[71] M. Weinreb, D. Shinar, G. A. Rodan, J. Bone Miner. Res. 2009, 5, 831. 